\title{
Incidence of Fascioliasis Invasion and The Effect of The Disease on Some Hematological and Blood Biochemical Parameters in Sheep Breeding in Afyonkarahisar Province
}

\author{
Bülent ELİTOK* \\ Afyon Kocatepe University, Faculty of Veterinary Medicine, Department of Internal Medicine-03200, Afyonkarahisar - Turkey
}

\begin{abstract}
This study was carried out in forty-six sheep aged between 1 and 4 years old breeding in Afyonkarahisar Province. Totally 23 animals that were found to have fascioliasis as a result of the stool examinations of 127 animals assigned as the study group, while clinically healthy 23 animals at the same age served as control group. All the clinical, hematological and biochemical parameters were measured in all the animals. As a result of the measurements showed that there was no statistically significant difference between the groups in terms of body temperature, whereas, mean heart and respiratory frequencies, eosinophil count, aspartate aminotransferase, gamma-glutamyl transferase, total and direct bilirubin levels were higher in animals with fascioliasis, while glucose, albumin and total protein levels were decreased. At the end of the study, it was concluded that despite all treatment options, fascioliasis still had a high incidence, and hematological and biochemical parameters could make important contributions to the early diagnosis and treatment of the disease.
\end{abstract}

Keywords: Biochemistry, fascioliasis, findings, hematology, sheep

Afyonkarahisar İlinde Yetiştirilen Koyunlarda Fascioliasis İnvazyonun Görülme S1klı̆g ile Enfeksiyonun Bazı Hematolojik ve Biyokimyasal Parametreler Üzerine Etkisi

ÖZ

Bu çalışma Afyonkarahisar İli'nde yetiştirilen, yaşları 1-4 arasında değişen, 127 baş koyunda yapılmıştır. Yapılan dışkı muayenelerinde fascioliasis etkeni barındırdıkları tespit edilen 23 hayvan çalışma grubunu oluştururken, klinik olarak sağl1klı oldukları tespit edilen aynı yaşlardaki 23 koyun ise kontrol grubunu oluşturmuştur. Hayvanların tümünde bazı klinik, hematolojik ve biyokimyasal parametrelerin ölçümleri yapılmıştır. Yapılan ölçümler sonucunda; vücut sıcaklığı açısından gruplar arasında istatistiki açıdan önemli bir fark gözlenmezken, kalp ve solunum frekansları ortalamalar1, eozinofil sayıs1, aspartat aminotransferaz, gamma-glutamil transferaz, total ve direk bilirubin düzeylerinin fascioliasisli hayvanlarda yüksek, buna karşıllk glukoz, albümin ve total protein düzeylerinin ise azalmış olduğu tespit edilmiştir. Çalışmanın sonunda; fascioliasisin tüm tedavi imkanlarına rağmen hala yüksek sayllabilecek bir insidansa sahip olduğu, hematolojik ve biyokimyasal parametrelerin hastalığın erken tanı ve tedavisi açısından önemli katkılar sağlayabileceği sonucuna varılmıştır.

Anahtar Kelimeler: Biyokimya, bulgular, fascioliasis, hematoloji, koyun

To cite this article: Elitok. B. Incidence of Fascioliasis Invasion and The Effect of The Disease on Some Hematological and Blood Biochemical Parameters in Sheep Breeding in Afyonkarahisar Province. Kocatepe Vet J. (2019) 12(3):317-321 


\section{GİRİŞ}

Fascioliasis tüm dünyada olduğu gibi ülkemizde de koyunlar başta olmak üzere, sığır, keçi, manda ve daha bir çok hayvan türünde karşılaşılan, sporadik olarak insanlarda görülebilen (Özkan ve ark. 2005, Moghadami ve Mardani 2008, Emir ve ark. 2013, Odabaşı ve ark. 2014), Lymnea truncatula adlı arakonakçısı bulunan, yaprak veya kelebek şeklindeki helmintlerin oluşturduğu bir enfeksiyondur (Kleigman ve ark. 2007, Blood ve Radostits 2007, Tinar 2011).

Akut ve kronik seyredebilen enfeksiyon sirasinda koyunlarda fascioliasis etkenleri (Fasciola hepatica, Fascola gigantica) büyüme geriliği, canlı ağırlık ve verim kayıplar1, immun sistemin baskılanmas1 ve ileri olgularda ölüme yol açabilmektedir (Hawkins 1984, Mulcahy ve ark. 1999, Paz-silva ve ark. 2003). Ağız yoluyla alınarak duodenuma gelen metaserkerlerden serbest kalan trematodlar, barsak duvarına penetre olarak karaciğer kapsülü ve safra sistemine yerleşmektedirler. Fascioliasisin seyri sırasında ateş, hepatomegali, kilo kaybı, anemi ve eozinofili sıkça karşılaşılabilen bulgulardandır. Tedavi edilmeyip kronikleşen vakalarda ishal, kusma, kolestaz ve buna bağlı olarak gelişen sarılık gibi belirtiler gözlenebilmektedir (Vercelli-Retta ve ark. 2002, Akısü ve ark. 2004, Emir ve ark. 2013).

Klinik bulgulara göre hastalıktan şüphe duyulduğunda, dışkı muayeneleri yapilarak etkenlerinin yumurtalarınin saptanmasiyla kesin tanı konulmaktadır (Blood ve Radostits 2007). Hematolojik ve kan biyokimysal muayenelerinde eozinofili ve yüksek GGT düzeylerinin saptanmas1 sıklıkla tespit edilen bulgulardandır (Matanovic ve ark. 2007, Kleigman ve ark. 2007).

$\mathrm{Bu}$ çalışma, Afyonkarahisar İli'nde yetiştirilen koyunlarda fascioliasisin görülme sıklığ1 ile enfekte hayvanlarda oluşturduğu patolojik etkileri klinik, hematolojik ve biyokimyasal parametrelerle ortaya koymak amacıyla yapılmıştır.

\section{MATERYAL ve METOT}

$\mathrm{Bu}$ çalışmada, Afyonkarahisar İli'nde yetiştirilen yaşları 1-4 arasında değişen, 127 baş hayvanda yaptığımız dışk1 taramaları sonucunda fascioliasisli oldukları saptanan 23 baş koyun çalışma grubunu (ÇG) oluştururken, yapılan dişk1 muayenelerinde fascioliasis etkeni tespit edilmeyen ve klinik muayeneler sonucunda sağliklı oldukları saptanan ve aynı yetiştirme koşullarında barındırılan toplam 23 koyun ise kontrol grubunu (KG) oluşturmuştur. $\mathrm{Bu}$ çalışma AKUHADYEK B.30.2.AKU.0.A2.00.00/204 say1l referans numarasiyla, Afyon Kocatepe Üniversitesi Hayvan Deneyleri Etik Kurulu (AKUHADYEK) etik kuralları çerçevesinde yürütülmüştür.

\section{Klinik Muayeneler}

Her iki gruptaki hayvanlarda yöntemine (Blood ve Radostits 2007) uygun olarak rutin klinik muayeneler (vücut sıcakliğ1, kalp ve solunum frekansları) yapılmış ve elde edilen veriler kaydedilmiştir.

\section{Hematolojik Muayeneler}

$K G$ ve ÇG grubu hayvanların vena jugularis'lerinden kan örnekleri alınarak hematolojik muayeneleri yapılmıştır. Hematolojik muayenelerde; eritrosit (RBC), total lökosit (WBC), hematokrit (HCT), hemoglobin (HB), lenfosit (LENF), nötrofil (NOTR), eozinofil (EOZ), monosit (MON) ve bazofil (BAZ) gibi hematolojik muayeneler kan sayım cihaz ile ticari test kitleri kullanılarak ölçülmüştür.

\section{Kan Biyokimyasal Analizleri}

Çalışmanın materyalini oluşturan hayvanların tümünde alınan kan örneklerinde aspartat aminotransferaz (AST), gamma-glutamil transferaz (GGT), total protein (TP), albumin (ALB), kan üre nitrojeni (BUN), kreatinin (KREA), glukoz (GLU), total bilirubin (TB) ve direk bilirubin (DB) düzeyleri otoanalizatörde ticari test kitleri kullanilarak ölçülmüştür.

\section{Dışkı Muayeneleri}

Dışkıda fasciolia yumurtalarının mikroskobik tespiti Cawdery ve Ruane (1971) tarafindan daha önceleri bildirildiği şekilde sedimantasyon yöntemi kullanılarak yapılmış ve bu işlem için 1 şı mikroskobu kullanılmıştır.

\section{İstatistiksel Analizler}

Çalışmanın materyalini oluşturan gruplar açısından klinik, hematolojik ve kan biyokimyasal parametreleri arasındaki farklılıklar bağımsız örneklemler için t-testi (indipendent samples t-test) kullanilarak, SPSS 18.01. for Windows paket programında yapilmış, $\mathrm{p}<0.05$ istatistiki olarak önemli kabul edilmiştir.

\section{BULGULAR}

Hayvanlara ait klinik, hematolojik ve kan biyokimyasal muayene sonuçları Tablo 1-3'te gösterilmiştir.

\section{Klinik Bulgular}

Gruplara ait klinik bulgular Tablo 1'de gösterilmiştir. Tablo 1 incelendiğinde; ishal, öksürük, burun akıntısı gibi semptomlar KG ve ÇG hayvanların hiç birinde saptanmadığı, konjuktiva ve mukozaların muayenesinde grupların hiç birinde belirgin bir sarılık bulgusuna rastlanmadığı, ancak fascioliasis ile enfekte hayvanların canlı ağıllık kazanımlarının daha az olduğu gözlenmiştir. Alınan anamnez bulguları fascioliasisli dişi hayvanların süt verimlerinin de düşük olduğu şeklindeydi. Vücut sıcaklığı bakımından KG ile ÇG hayvanlar karşılaştırıldığında, istatistiki bir fark oluşmamasına rağmen, ÇG hayvanların vücut sıcaklı̆ğ ortalamalarının numerik olarak daha yüksek olduğu, 
buna karşılık solunum ve kalp frekansları ortalamalarının ÇG hayvanlarda istatistiksel açıdan önemli derecede $(\mathrm{p}<0.05)$ yüksek olduğu gözlenmiştir.

\section{Hematolojik Muayene Bulguları}

Çalışmada kullanılan hayvanların hematolojik muayene bulguları Tablo 2'de gösterilmiştir. Tablo 2 incelendiğinde; daha düşük LENF yüzdeleri ortalamasına karșlık WBC, EOZ, MON ve NOTR düzeyleri ortalamalarının ÇG hayvanlarda istatistiksel açıdan önemli derecede yüksek, RBC, HB, HCT ortalamalarının ise $\mathrm{KG}$ hayvanlardaki ortalamalarından anlamlı derecede $(\mathrm{p}<0.05)$ düşük olduğu gözlenmiştir.

\section{Biyokimyasal Analiz Bulguları}

KG ile karşılaştırıldığında, ölçümü yapılan AST ve GGT enzim düzeyleri ile TB ve DB konsantrasyonu ortalamalarının ÇG hayvanlarda yüksek, buna karşılık GLU, TP, ALB, BUN ve KREA düzeylerinin ise düşük ve aradaki farkların istatistiki açıdan önemli $(p<0.05)$ olduğu saptanmıştır (Tablo 3).

Tablo 1. Klinik muayene bulgular1

Table 1. Findings of the clinical examinations

\begin{tabular}{lccc}
\hline Grup/Semptom & KG & ÇG & P değeri \\
& $(\mathrm{n}=23)$ & $(\mathrm{n}=23)$ & - \\
\hline Çene veya karın altında ödem & - &,$+(\mathrm{n}=1)$ & - \\
İshal & - &,$+(\mathrm{n}=23)$ & - \\
Dişkı1da Fasciola spp. varlığ1 & - & $38.5 \pm 0.00$ \\
Vücut sıcaklığ1 ortalamaları (T $\left.{ }^{\circ} \mathrm{C}\right)$ & $38.1 \pm 0.20$ & $77.2 \pm 4.00$ \\
Kalp frekansı ortalamaları (frekans/dk) & $68.2 \pm 3.00$ & $34.3 \pm 1.20$ \\
Solunum frekansı ortalamaları (frekans/dk) & $25.2 \pm 0.20$ & $*$ \\
\hline *: p<0.05, KG: Kontrol grubu, ÇG: Çalışma grubu, (-): Tespit edilmedi, (+): Tespit edildi.
\end{tabular}

Tablo 2. Gruplara ait hematolojik muayene bulgular1

Table 2. Hematologic examination findings of the groups

\begin{tabular}{|c|c|c|c|c|c|c|c|c|c|}
\hline $\begin{array}{c}\text { Grup/ } \\
\text { Parametre }\end{array}$ & $\begin{array}{c}\text { WBC } \\
(/ \mathrm{mm} 3)\end{array}$ & $\begin{array}{c}\text { RBC } \\
(/ \mathrm{mm} 3)\end{array}$ & $\begin{array}{l}\text { HB } \\
(\mathrm{g} / \mathrm{dl})\end{array}$ & $\begin{array}{c}\text { HCT } \\
\%\end{array}$ & $\begin{array}{c}\text { LENF } \\
\%\end{array}$ & $\begin{array}{c}\text { NOTR } \\
\%\end{array}$ & $\underset{\%}{\mathrm{EOZ}}$ & $\underset{\%}{\text { MON }}$ & $\begin{array}{c}\text { BAS } \\
\%\end{array}$ \\
\hline & $\begin{array}{l}\text { Mean } \pm \\
\text { SEM }\end{array}$ & $\begin{array}{l}\text { Mean } \pm \\
\text { SEM }\end{array}$ & $\begin{array}{l}\text { Mean } \pm \\
\text { SEM }\end{array}$ & $\begin{array}{l}\text { Mean } \pm \\
\text { SEM }\end{array}$ & $\begin{array}{l}\text { Mean } \pm \\
\text { SEM }\end{array}$ & $\begin{array}{l}\text { Mean士 } \\
\text { SEM }\end{array}$ & $\begin{array}{l}\text { Mean士 } \\
\text { SEM }\end{array}$ & $\begin{array}{l}\text { Mean } \pm \\
\text { SEM }\end{array}$ & $\begin{array}{l}\text { Mean士 } \\
\text { SEM }\end{array}$ \\
\hline KG & $8.23 \pm 1.16$ & $8.24 \pm 1.46$ & $10.20 \pm 1.18$ & $27.20 \pm 1.32$ & $56.18 \pm 2.10$ & $41.10 \pm 2.30$ & $2.00 \pm 1.00$ & $1.00 \pm 0.00$ & $0.01 \pm 0.00$ \\
\hline ÇG & $11.04 \pm 1.34$ & $5.21 \pm 1.18$ & $6.28 \pm 2.10$ & $18.32 \pm 2.22$ & $33.24 \pm 3.10$ & $54.24 \pm 3.10$ & $8.20 \pm 2.10$ & $4.20 \pm 1.10$ & $0.01 \pm 0.00$ \\
\hline
\end{tabular}

*: p >0.05, **: p<0.05, ***: p<0.01, KG: Kontrol grubu, ÇG: Çalışma grubu

Tablo 3. Gruplara ait kan biyokimyasal analiz bulgular1

Table 3. Blood biochemical analysis findings of the groups

\begin{tabular}{|c|c|c|c|c|c|c|c|c|c|}
\hline \multirow{2}{*}{$\begin{array}{c}\text { Grup/ } \\
\text { Parametre }\end{array}$} & $\begin{array}{c}\text { AST } \\
(\mathrm{IU} / \mathrm{L})\end{array}$ & $\begin{array}{c}\text { GGT } \\
(\mathrm{IU} / \mathrm{L})\end{array}$ & $\begin{array}{c}\mathbf{T P} \\
(\mathrm{g} / \mathrm{L})\end{array}$ & $\begin{array}{l}\text { ALB } \\
(g / L)\end{array}$ & $\begin{array}{l}\text { GLU } \\
(\mathrm{g} / \mathrm{L})\end{array}$ & $\begin{array}{c}\text { BUN } \\
(\mathrm{mmol} / \mathrm{L})\end{array}$ & $\begin{array}{c}\text { KREA } \\
(\mu \mathrm{mol} / \mathrm{L})\end{array}$ & $\begin{array}{c}\text { TB } \\
(\mu \mathrm{mol} / \mathrm{L})\end{array}$ & $\begin{array}{c}\text { DB } \\
(\mu \mathrm{mol} / \mathrm{L})\end{array}$ \\
\hline & $\begin{array}{l}\text { Mean } \pm \\
\text { SEM }\end{array}$ & $\begin{array}{l}\text { Mean } \pm \\
\text { SEM }\end{array}$ & $\begin{array}{l}\text { Mean } \pm \\
\text { SEM }\end{array}$ & $\begin{array}{l}\text { Mean } \pm \\
\text { SEM }\end{array}$ & $\begin{array}{l}\text { Mean } \pm \\
\text { SEM }\end{array}$ & $\begin{array}{l}\text { Mean } \pm \\
\text { SEM }\end{array}$ & $\begin{array}{l}\text { Mean } \pm \\
\text { SEM }\end{array}$ & $\begin{array}{l}\text { Mean } \pm \\
\text { SEM }\end{array}$ & Mean \pm SEM \\
\hline \multirow[t]{2}{*}{ KG } & & & & & $64.48 \pm 2.24$ & & & & \\
\hline & $84.16 \pm 10.20$ & $36.24 \pm 3.18$ & $78.12 \pm 2.34$ & $33.43 \pm 0.44$ & & $1.58 \pm 0.32$ & $56.13 \pm 2.22$ & $2.85 \pm 0.40$ & $1.12 \pm 0.04$ \\
\hline ÇG & $\begin{array}{c}178.18 \pm 12.3 \\
0\end{array}$ & $74.02 \pm 4.16$ & $65.47 \pm 3.26$ & $21.60 \pm 0.28$ & $43.38 \pm 3.14$ & $2.22 \pm 0.30$ & $74.32 \pm 3.16$ & $4.02 \pm 0.53$ & $2.68 . \pm 0.05$ \\
\hline P değeri & $* * *$ & $* * *$ & ** & $* *$ & $* * *$ & $*$ & ** & $* *$ & * \\
\hline
\end{tabular}

*: p >0.05, **: p<0.05, ***: p<0.01, KG: Kontrol grubu, ÇG: Çalışma grubu 


\section{TARTIŞMA}

Çalışmamızın başlangıcında fascioliasis etkenleri tespit etmek amacıyla dışkı taramaları yaptığımız 127 hayvandan 23 tanesinde etken tespit etmemiz, hastalığın görülme sıklığının \%18.1 'lik bir oranda olduğunu göstermektedir. Küçük çapta bir prevalans çalışması olarak kabul edildiğinde, çalışmanın yapıldığ bölgede daha önceleri koyunlarda yapilan prevalans çalıșmasına rastlayamadığımızdan, elde etiğimiz bu oranı, karşılaştırma imkanımız da olmamıştır. Ancak gaita muayenesi ile fascioliasis etkeni tespitine dayalı daha önceleri yapılan çalışmalarda hastalığın görülme sıklığ1; İstanbul, Samsun ve Ordu, Konya, Elazığ, Van, Trakya bölgesi, Kırıkkale, Şanlıurfa bölgelerinde sirasiyla \%6, \%18.1-30.2, \%12.9, \%16.1, \%0.3-15.9, \%3.9-95, \%0.6 ve \%1.9 olarak bildirilmiştir (Denizhan ve Biçek 2018). Bu verilerden de anlaşılacağı üzere enfeksiyonun prevalansı bölgelere göre büyük farkllılıklar göstermektedir. Bu farklılığın en önemli nedenleri hayvanların yetiştirme tarz1 ve barındırıldıkları alan, iklim ve mevsimdir (Blood ve Radostits 2007). Nitekim, yağışlı mevsimlerden sonra, sular altında kalan meralarda, 10 ila $25^{\circ} \mathrm{C}$ arasındaki sıcaklıkta ve düşük rakımda yetiştirilen hayvanlarda yapılan bir araştırmada (Andrews, 1999), anılan koşullarda arakonakçılarının popülasyonlarının arttığı ve bu meralarda yetiştirilen hayvanlarda fascioliasisin yüksek insidenste seyrettiği bildirilmiştir. Fasciola spp. prevalansının yağmurları takiben kanal boylarında yetişen otlara tutunan serkerlerin ve salyangoz sayılarının artmasıyla doğrudan ilişkilidir (Paz-Silva ve ark. 2003). Yağmurlu havaların hüküm sürdügü iklimlerde fascioliasisin prevalansı hakkında farklı veriler rapor edilmekle birlikte, etkenlerin ve arakonakçıların özellikle nemli ve bulutlu iklim koşullarında daha uzun süre yaşadıkları bildirilmiştir (Mamun ve ark. 2011). Çalışmanın yapıldığ1 Afyonkarahisar İli önceleri kurak bir iklime sahip olmakla birlikte, özellikle son zamanlarda yapilan baraj sayısındaki artışa ve iklimsel değişikliklere paralel olarak, sürekli yağmurların hüküm sürdügü ve bulutlu havaların yoğun görüldüğü bir yer haline gelmiştir. Ayrıca, çalışmanın materyalini oluşturan hayvanların otlaklara salınması ve bu otlakların su kaynaklarına yakın olmaları, bu parazit ile ilgili saptadığımız prevalansı açıklamaya yardımcı olmaktadır.

Yaptığımız çalışmada $K G$ ve ÇG arasında vücut sıcaklığ açısından istatistiki açıdan önemli bir fark gözlenmemekle birlikte, kalp ve solunum frekanslarının istatistiksel açıdan önemli derecede artmış olması, solunumun kompenzasyonuna bağlanabilir. Nitekim, hematolojik muayenelerde RBC sayısı ortalamasının ÇG hayvanlarda önemli derecede düşük ve buna $\mathrm{HB}$ ve HCT düzeylerinin eşlik ettiği açıkça görülmektedir. Bizim bulduğumuz sonuçlara benzer şekilde, fascioliasisle doğal enfekte 214 koyunda yapılan bir çalışmada, Haroun ve ark. (2009), RBC, HCT ve HB sayılarının azaldığı, normositik- nomrokronik bir anemi ve bu hayvanlarda lökositoz ile birlikte eozinofili tablosunun geliştiğini bildirmişlerdir.

Araştırmamızda KG ile karşılaştırıldığında, WBC, NOTR, MON ve EOZ düzeylerinin ÇG grubu hayvanlarda oldukça yüksek olduğu ve eozinofili tablosunun hakim olduğu dikkati çekmiştir. Öyle ki, Akısü ve ark. (2004), fascioliasis enfestasyonunda EOZ sayısındaki artışını, oldukça yüksek bir oranda, $\% 50$ olarak bildirmişlerdir. (2009). Ayrica bu çalışmadan elde ettiğimiz tüm bu hematolojik bulgular, fascioliasisli hayvanlarda LENF düzeylerinin azaldı̆̆ı, buna karşılık EOZ, NOTR, MON ve WBC düzeylerinin artış gösterdiğini bildiren araştırıcıların (Resende ve ark. 2007) saptadıkları bulgular ile tam bir uyum içerisindedir.

$\mathrm{Bu}$ çalışmada KG hayvanlar ile karşılaştırıldığında; AST ve GGT enzim düzeyleri ile TB ve DB konsantrasyonları ortalamalarının ÇG hayvanlarda anlamlı derecede yüksek, buna karşılık GLU, BUN, KREA, TP ve ALB düzeyleri ortalamalarının ise önemli derecede düşük olduğu saptanmıştır. Matanovic ve ark. (2007), ölçümünü yaptığımız bazı parametreler açısından elde ettiğimiz bulgulara benzer sonuçlar bildirmelerine rağmen, farklı olarak, AST düzeyinde anlamlı bir azalma şekillendiğini iddia etmişlerdir. Hodzic ve ark. (2013) ise, fascioliasis olgularında AST düzeylerinin önemli bir değişim göstermediğini bildirmişlerdir. Elde ettiğimiz yüksek AST düzeyleri bu yönüyle, bu araştırmacıların bulguları ile farkllık arz ederken, fascioliasis enfeksiyonu sırasında AST dahil karaciğer enzimlerinde yükselme olabileceğini bildiren diğer araştırmaciların (Scott ve ark. 2005, Mert ve ark. 2006, Emir ve ark. 2013) bulgulariyla uyum göstermektedir.

Swarupd ve ark. (1986), fascioliasis invazyonu sırasında TP düzeylerinin değişmediğini bildirmelerine rağmen, yaptığımı çalışmada KG ile karşılaştırıldığında enfekte hayvanların TP düzeylerinin önemli derecede azaldığı saptanmış ve bu azalmanın sebebi olarak, TP fraksiyonlarından birisini oluşturduğu için, ALB düzeylerindeki azalmaya bağlanmıştır.

Mevcut çalışmamızda klinik bakıda sarılık tablosu gözlenmemesine ve biyokimyasal muayenelerde her iki grup ortalamalarının fizyolojik sınırlar içerisinde (Blood ve Radostits 2007) bulunmasına rağmen, TB ve $\mathrm{DB}$ düzeyleri ortalamalarının ÇG hayvanlarda istatistiksel açıdan önemli derecede yüksek olduğu gözlerden kaçmamıştır. Benzer bulguları daha önceleri tespit eden Hodzic ve ark. (2013), bu durumun fascioliasis etkenlerinin salgiladıkları hemolitik toksinlerden ve hastalığın seyri sırasında safra sisteminin gördüğü hasardan kaynaklanabileceğini bildirmişlerdir. 


\section{SONUÇ}

$\mathrm{Bu}$ çalışmada elde ettiğimiz bulgular işığında, koyunlarda fascioliasis enfeksiyonu ile ilgili klinik bulguların hastalığın tanısında her zaman yeterli olamayacağ1, ayrıca iklimsel değişiklikler göz önüne alındığında, fascioliasisin tüm tedavi imkanlarına rağmen hala yüksek sayılabilecek bir insidansa sahip olduğu, hayvanların sağlık durumlarının tespitinde ve enfeksiyondan ne derecede etkilendiğinin belirlenmesinde, fasciolazisin erken tanı, tedavi ve prognozunda hematolojik ve biyokimyasal parametrelerin ölçümlerinin oldukça değerli katkılar sağlayabileceği sonucuna varılmıştır.

\section{TEŞEKKÜR}

Bu çalışma AKUHADYEK B. 30. 2. AKU.0.A2.00.00/204 sayli referans numaraszyla, Afyon Kocatepe Üniversitesi Hayvan Deneyleri Etik Kurulu (AKUHADYEK) etik kurallar çercevesinde yürütülmüstür.

\section{KAYNAKLAR}

Akısü Ç, Meral M, Delibaş SB, Güngör Ö, Aksoy Ü, Sağol Ö, Tankurt E. Fasciolosis; a case with eosinophilic granuloma in the liver . Turkiye Klinikleri J Gastroenterohepatol. 2004; 15: 89-92.

Andrews SJ. The life cycle of Fasciola hepatica. In: Dalton J. (Ed.). Fasciolosis. CAB International, New York, USA, 1999; pp.1-20.

Blood DC, Radostits OM. Veterinary Medicine. Bailliere Tindall, London, UK, 2007.

Cawdery M, Ruane M. Sedimentation method for the demonstration of the eggs of Fasciola bepatica in faeces. Lab Pract. 1971; 20: 935-941.

Denizhan V, Biçek K. Van İli ve Bazı İlçelerinde Koyunlarda Fasciola bepatica'nın Seroprevalansı. Atatürk Üniversitesi Vet Bil Derg. 2018; 13(3): 278-284.

Emir S, Yazar MF, Sözen S, Altınsoy HB, Bulut HT , Özkan Z. Fasciola Hepatica'ya bağlı olarak gelişen akut kolanjit ve pankreatit: Olgu Sunumu. ADÜ Tip Fak Derg. 2013; 14(3):27-29

Haroun EM, Gadir AH, Gameel AA. Studies on naturallyoccurring ovine fascioliasis in the Sudan. J Helminthol. 1986; 60(1): 47-53.

Hawkins CD. The use of haemoglobin, packed-cell volume and serum sorbitol dehydrogenase as indicators of the development of fascioliasis in sheep. Vet Parasitol. 1984; 15:125-133.

Hodzic A, Zuko A, Avdic R, Alic A, Omeragci J, Jazic A. Influence of Fasciola hepatica on serum biochemical parameters and vascular and biliary system of sheep liver. Iranian J Parasitol. 2013; 8(1):92-98.

Kliegman RM, Behrman RE, Jenson HB, Stanton BF. Nelson textbook of pediatrics,18th ed. WB Saunders Elsevier, Philadelphia, USA, 2007.

Mamun MA, Bhuiyan MJU, Zinnah MA, Hassan MM, Atikuzzaman M, Uddin MB. Ruminantlarda Fasciola sp. enfeksiyonunun prevalansi. Eurasian J Vet Sci. 2011; 27(4): 241-244.
Matanovic K., Severin K., Martinkovic F. Simpraga M, Janicki Z. Barisic J. Hematological and biochemical changes in organically farmed sheep naturally infected with Fasciola bepatica. Parasitol Res. 2007; 101: 1657-61.

Mert H, Kozat S, Ekin S, Mert N, Yörük I. Serum sialic acid, lipid-bound sialic acid levels in sheep naturally chronic infected with Fasciola hepatica. Sag Bil Derg. 2006; 9: 4046.

Moghadami M, Mardani M. Fasciola hepatica: a cause of obstructive jaundice in an elderly man from Iran. Saudi J Gastroenterol . 2008;14(4): 208-210.

Mulcahy G, O'Connor F, Clery D, Hogan SF, Dowd AJ, Andrews SJ, Dalton JP. Immune responses of cattle to experimental anti-Fasciola hepatica vaccines. Res Vet Sci. 1999; 67:27-33.

Odabaşı H, Yıldız M, Eriş C, Abuoğlu H, Günay E, Özkan E, Müftüoğlu T. Fasciola bepatica tanısinda endosonografinin rolü. Gastrointest Endosc. 2014; 22 (1):21-24.

Özkan AT, Korkmaz M, Kuman A, Ayçiçek H, Tanyüksel M. Fascioliasis tanısında erişkin antijeni ile PBS ve RPMI 1640'da elde edilen ekskresyon/sekresyon antijenlerinin Elisa yöntemiyle karşılaştırılması. Türk Hij Den Biyol Derg. 2005; 62 (1-3):1 -26.

Paz-Silva A, Sanchez-Andrade R, Suarez JL, Pedreira R, Arias M, Lopez C, Panadero R, Diaz P, Diez Bonos P. Prevalence of natural ovine fasciolosis shown by demonstrating the presence of serum circulating antigens. Parasitol Res. 2003; 91: 328.

Resende COT, Hirsch CS, Toossi Z, Dietze R, RibeiroRodrigues R. Intestinal helminth co-infection has a negative impact on both anti-Mycobacterium tuberculosis immunity and clinical response to tuberculosis therapy. Clin Experim Immunol. 2007; 147(1): 45-52.

Scott PR, Sargison ND, Macrae A, Rhind SR. An outbreak of subacute fasciolosis in Soay sheep: Ultrasonographic biochemical and histological studies. The Vet J. 2005; 170(3): 325-331

Swarup D, Upadhyays DS, Pachaurip SP. Some biochemical indices in naturally occurring fascioliasis in goats. Res Vet Sci.1986; 40(2): 276-277.

Tınar R. Veteriner Helmintoloji. Dora Basım-Yayın Ltd. Şti., Bursa, 2011.

Vercelli-Retta J, Lagios MD, Chandrasoma P. Fasciola hepatica and parasitic eosinophilic granuloma of the liver. Am J Surg Pathol 2002; 26(9): 1238. 